Check for updates

Cite this: RSC Adv., 2018, 8, 27565

Received 12th June 2018 Accepted 18th July 2018

DOI: $10.1039 / c 8 r a 05032 e$

rsc.li/rsc-advances

\section{Synthesis of zirconium modified FDU-12 by different methods and its application in dibenzothiophene hydrodesulfurization $\uparrow$}

\author{
Qian Meng, Peng Du, Bo Wang, Aijun Duan, (D) * Chunming Xu, ${ }^{*}$ Zhen Zhao, \\ Cong Liu, Di Hu, Yuyang Li and Chengkun Xiao
}

Zirconium modified mesoporous materials were successfully synthesized by different methods including direct synthesis and post synthesis (grafting and impregnating). Meanwhile, the corresponding catalysts were prepared. A series of techniques, including small-angle X-ray scattering (SAXS), transmission electron microscopy (TEM) and pyridine adsorption Fourier-transform infrared (Py-IR), were used to characterize the properties of supports and catalysts. The results of SASX and TEM characterization proved that all the modified materials retained the wellordered mesoporous structure from the FDU-12 material. $\mathrm{N}_{2}$ adsorption-desorption results showed that the $\mathrm{Zr}$ FDU-12 material obtained by direct synthesis ( $\mathrm{Zr}$-in-F) possessed higher specific surface area $\left(709 \mathrm{~m}^{2} \mathrm{~g}^{-1}\right)$, pore volume $\left(0.65 \mathrm{~cm}^{3} \mathrm{~g}^{-1}\right)$ and larger pore size $(18.7 \mathrm{~nm})$ than the $\mathrm{Zr}$-FDU-12 materials obtained by the post synthesis. According to the characterization result of UV-Vis, Zr-in-F exhibited better dispersion of $\mathrm{Zr}$ species than materials obtained by the post synthesis. It was found that the incorporation of $\mathrm{Zr}$ species not only increased acidities but also enhanced the sulfidities of the Mo species. All the catalysts were evaluated for their activities in the hydrodesulfurization of dibenzothiophene, and the NiMo/Zr-in-F catalyst exhibited the best catalytic performance (97.3\%), attributed to its higher specific surface area, larger pore size, higher sulfidity, and more acidic sites.

\section{Introduction}

With the legislation of environmental protection becoming more severe, vehicle fuel specifications have been published in many developed countries, especially for the control of sulfur content to near zero..$^{1-4}$ As far as we all know, sulfur-containing. compounds in oil can be removed by many techniques, including hydrotreating, adsorption desulfurization, oxidative desulfurization and biological desulfurization processes, in particular the hydrotreating process is currently the most used in the refinery industry. ${ }^{5}$ Catalysts usually play a significant role in the hydrotreating process, and their excellent physicochemical properties can help active metal dispersion and promote the diffusion of the reactants and products. As the typical refractory molecule, 4,6-DMDBT has apparent steric hindrance, due to the adjacent substitutes of methyl at 4 and 6 positions, it is difficult for it to be removed over the traditional catalysts under the typical operation conditions. Thus the development of catalysts with high activity will be an effective thrust toward hydrodesulfurization. ${ }^{6,7}$

State Key Laboratory of Heavy Oil Processing, China University of Petroleum, Beijing, 102249, P. R. China.E-mail:duanaijun@cup.edu.cn; xcm@cup.edu.cn

$\dagger$ Electronic supplementary information (ESI) available. See DOI: 10.1039/c8ra05032e
The activity of catalysts is restricted by many factors, among which the support contributes greatly, thus the development of new catalysts greatly depends on the supports. $\mathrm{Al}_{2} \mathrm{O}_{3}{ }^{8,9}$ the representative of the traditional supports, possesses many good properties, such as excellent mechanical strength and low-price, however, its strong metal and support interaction (MSI) influences the aggregation states of active metals, then hinders the formation of type II-active phases with suitable stacks. ${ }^{10}$ Nowadays many carriers, including $\mathrm{ZrO}_{2},{ }^{11,12} \mathrm{TiO}_{2},{ }^{13,14}$ and $\mathrm{SiO}_{2}$ (ref. 15-17) are used in hydrodesulfurization. Interestingly, mesoporous silica materials with high specific surface area, large pore volume and uniformly adjustable aperture $(2-50 \mathrm{~nm})$, attract much more attention of the scientific researchers, of which the advantages apparently make them to be the superior candidates in the field of adsorption, catalysis and biomedicine. With the application of mesoporous silica materials, however, the apparent limitation of the mesoporous materials reveals their low hydroxyl density on the surface, which makes a weak interaction between support and active metal, leading to inhomogeneous dispersion of active species. In order to improve the surface property of mesoporous silica materials, the researchers tried to embed the heteroatoms into the framework of mesoporous silica materials, such as $\mathrm{Al}^{3+}, \mathrm{Zr}^{4+}$ and $\mathrm{Ti}^{4+} \cdot{ }^{18-21}$

It was found that the incorporation of heteroatoms was executed by two main methods: direct synthesis and post synthesis (grafting or impregnating). ${ }^{21-26}$ The direct synthesis 
shows the advantages of: (1) better dispersion of heteroatoms; (2) the better connectivity of the pores. Li et $a .^{22}$ reported a direct synthesis of mesoporous material Zr-SBA-15 using cationic hexadecyltrimethylammonium bromide and non-ionic triblock copolymer Pluronic (P123) as the templates. According to the characterization results, $\mathrm{Zr}$ species were fully dispersed in the structure of SBA-15 when $\mathrm{Zr} / \mathrm{Si}$ molar ratio is lower than 0.68. Olivas et $a .^{23}$ recently obtained Ti-containing and Alcontaining SBA-15 by a direct-synthesis method, and the result showed most $\mathrm{Ti}$ species and $\mathrm{Al}$ species were incorporated into the framework of mesoporous SBA-15. The modified SBA15 material had little difference with the pure SBA-15 material in specific surface area, volume and pore size, which indicated a good retaining of the connectivity of mesopore channels. However, there are two mainly challenges in the process of direct synthesis: (1) the local distortion of framework due to the effect of $\mathrm{Zr}$ species on the assembly of silicon species. (2) The difficult formation of the $\mathrm{Me}-\mathrm{O}-\mathrm{Si}$ bond. Since the post synthesis method is to process the materials that have been prepared, thus it can avoid the problem of framework distortion. ${ }^{24}$ Nevertheless, the apparent disadvantages also need to be noted: some isolated external-skeleton species form to the small particles in the post process, which result in the blockage of the pores channels, consequently decreasing the specific surface area and volume. Klimova Tatiana et $a{ }^{25}{ }^{25}$ successfully synthesized a series of SBA-15 modified with aluminum oxide $\left(\mathrm{Al}_{2} \mathrm{O}_{3}\right)$ or transition metal oxides $\left(\mathrm{TiO}_{2}, \mathrm{ZrO}_{2}\right)$ by chemical grafting. It was found that the surface area and pore volume of the material were greatly reduced after modification, especially for the transition metal oxides. Wang et al. ${ }^{21}$ recorded the same phenomenon in the process of synthesizing Zr-MCFs material, especially at a low ratio of $\mathrm{Si} / \mathrm{Zr}$, which was ascribed to the formation of $\mathrm{ZrO}_{2}$ particles.

The excellent HDS catalysts should have not only the well dispersion of the active metals, but also the excellent mass transfer performance. Zhao Dongyuan group firstly synthesized three-dimensional highly ordered face-centred cubic (Fm3m) mesoporous silica material FDU-12 using triblock copolymers (F127) as the template, ${ }^{27}$ of which the structure was very favorable to the diffusion of reactants and products. In previous research, Cao et al. $^{28}$ reported the synthesis of Ti-FDU-12 through a two-step method of prehydrolysis of TEOS followed by addition of titanium butoxide as a titanium precursor, and the catalyst with the $\mathrm{Si} / \mathrm{Ti}$ ratio of 5.0 exhibited the highest catalytic performance in hydrodesulfurization of DBT and 4,6DMDBT. Wang et al. ${ }^{29}$ synthesized different morphologies FDU12 materials using different inorganic salts as the additives, and they all exhibited better catalytic performance in hydrodesulfurization with DBT as the probe molecules. It is clearly identified that FDU-12 has great potential to be the catalyst support for hydrodesulfurization.

In the present work, a series of mesoporous $\mathrm{Zr}-\mathrm{F}$ materials were successfully synthesized with a $\mathrm{Si} / \mathrm{Zr}$ molar ratio of 20 through three different methods, including the direct synthesis, grafting and impregnation. The corresponding NiMo/Zr-F catalysts obtained by different modified methods were prepared by a two-step incipient wetness method. The results of variable characterization methods demonstrated that all the assynthesized materials kept better ordered mesoporous structures. The catalytic performances of the catalysts were evaluated on the hydrodesulfurization using DBT as probe molecule under $613 \mathrm{~K}, 4 \mathrm{MPa}$ and different WHSVs $\left(20-150 \mathrm{~h}^{-1}\right)$. The contributions of different methods to incorporate $\mathrm{Zr}$ into the catalysts were discussed in detail.

\section{Experimental}

\subsection{Synthesis of materials}

Mesoporous FDU-12 material was synthesized using nonionic triblock copolymer (F127, Sigma Aldrich) as structure-directing agent, 1,3,5-trimethylbenzene (TMB, Aladdin) as the pore expanding agent, and tetraethylorthosilicate (TEOS) as the silica source. Furthermore, the incorporation of $\mathrm{Zr}$ to the support materials was realized by three different methods, involving direct synthesis, grafting and impregnation methods, of which zirconium oxychloride octahydrate $\left(\mathrm{ZrOCl}_{2} \cdot 8 \mathrm{H}_{2} \mathrm{O}\right)$ was taken as Zr source. All the chemical agents were used directly without further purifications.

Pure mesoporous silica FDU-12 was prepared according to the method reported in the literature. ${ }^{27}$ Typically, $2.0 \mathrm{~g}$ of F127 and $5.0 \mathrm{~g}$ of $\mathrm{KCl}$ were dissolved in $120 \mathrm{ml}$ of $2.0 \mathrm{M} \mathrm{HCl}$ with stirring until the mixture became a clear solution. Then, $2.0 \mathrm{~g}$ of TMB was added into the above solution. The mixture was stirred at $288 \mathrm{~K}$ for $24 \mathrm{~h}$ before $8.3 \mathrm{~g}$ of TEOS was added. Afterwards, the mixture continued to be stirred for $24 \mathrm{~h}$, and heated statically at $373 \mathrm{~K}$ in a Teflon autoclave. The solid product was obtained by filtering with distilled water, drying at $373 \mathrm{~K}$ in air, and calcined at $823 \mathrm{~K}$ for $6 \mathrm{~h}$ to remove the templates.

Direct synthesis. Zirconia-modified FDU-12 with a specific $\mathrm{Si} / \mathrm{Zr}$ molar ratio of 20 , noted as $\mathrm{Zr}-\mathrm{F}$, was hydrothermally synthesized through the direct methods. ${ }^{22,23}$ The detailed procedure of the synthesis is as follows: firstly, added $2.0 \mathrm{~g}$ of F127, $5.0 \mathrm{~g}$ of $\mathrm{KCl}$ and $2.0 \mathrm{~g}$ of TMB into $120 \mathrm{ml}$ of $2.0 \mathrm{M} \mathrm{HCl}$, then stirred for $24 \mathrm{~h}$ to form a homogeneous solution; secondly, added $8.3 \mathrm{~g}$ of TEOS into the solution and stirred for 2-4 h. Afterwards, $0.64 \mathrm{~g}$ of $\mathrm{Zr}$ source was added into the mixture and stirred vigorously for further $24 \mathrm{~h}$. Finally, the mixture was transferred into a Teflon autoclave and heated at $373 \mathrm{~K}$ for another $48 \mathrm{~h}$. The product was obtained by filtering, washing with distilled water, drying at $373 \mathrm{~K}$ in air, and calcined at $823 \mathrm{~K}$ for $6 \mathrm{~h}$. The as-prepared sample was denoted as Zr-in-F.

Post synthesis. The $\mathrm{Zr}-\mathrm{F}$ materials prepared by the post synthesis methods, including (grafting and impregnation) were described as below. ${ }^{21,24,25}$ The mass ratio of the $\mathrm{Zr}$ source to the support is kept at 0.270 .

a Grafting. At first, $\mathrm{Zr}$ source was dissolved in absolute ethanol and stirred at room temperature. Then, the pure FDU12 support was added into the above solution with stirring at $353 \mathrm{~K}$ for $4 \mathrm{~h}$. Afterwards, the mixture was filtered, washed with distilled water, dried at $353 \mathrm{~K}$ for $12 \mathrm{~h}$, and calcined at $823 \mathrm{~K}$ for $6 \mathrm{~h}$. Then, the obtained sample was denoted as Zr-gra-F.

$b$ Impregnating. Firstly, the pure FDU-12 material was dried at $373 \mathrm{~K}$ for 3-4 $\mathrm{h}$ in order to remove the water adsorbed in the pores. Then, Zr source ethanol solution, of which the volume 
was equal to the pore volume of the material, was added dropwise into the dried support by the incipient wetness method. After ultrasonic treatment for $15 \mathrm{~min}$, the solid was dried at $353 \mathrm{~K}$ for $12 \mathrm{~h}$, and calcined at $823 \mathrm{~K}$ for $6 \mathrm{~h}$. Finally, the product obtained was denoted as Zr-im-F.

\subsection{Catalysts preparation}

The supported catalysts NiMo/Zr-F (including NiMo/Zr-in-F, NiMo/Zr-im-F and NiMo/Zr-gra-F) with different modified methods were prepared via a two-step incipient wetness method. The heptamolybdate tetrahydrate $\left(\left(\mathrm{NH}_{4}\right)_{6} \mathrm{Mo}_{7} \mathrm{O}_{24} \cdot 4 \mathrm{H}_{2} \mathrm{O}\right)$ and nickel nitrate hexahydrate $\left(\mathrm{Ni}\left(\mathrm{NO}_{3}\right)_{2} \cdot 6 \mathrm{H}_{2} \mathrm{O}\right)$ were used to be Mo and $\mathrm{Ni}$ precursors respectively, with the loadings of $12 \% \mathrm{MoO}_{3}$ and $3 \% \mathrm{NiO}$ in series impregnation. After each impregnation step, the sample was treated using ultrasonic for $15 \mathrm{~min}$, dried at $373 \mathrm{~K}$ for $6 \mathrm{~h}$, and calcined at $823 \mathrm{~K}$ for $6 \mathrm{~h}$. Afterwards, the catalysts were obtained, donated as NiMo/Zr-in-F, NiMo/Zr-gra-F and NiMo/Zr-im-F respectively. In order to compare with the modified catalysts, $\mathrm{NiMo} / \mathrm{FDU}-12$ and $\mathrm{NiMo} / \mathrm{Al}_{2} \mathrm{O}_{3}$ catalysts were also prepared to be the reference catalysts.

\subsection{Characterizations of supports and catalysts}

Small-angle X-ray scattering (SAXS) patterns were tested on a Nano STAR Small-Angle X-ray scattering system (broker, Germany) using $\mathrm{Cu} \mathrm{K} \alpha$ radiation $(40 \mathrm{kV}, 35 \mathrm{~mA})$.

Fourier transform infrared spectroscopy (FTIR) absorbance spectra were performed with a FTS-3000 spectrophotometer, and the wave numbers ranged from 4000 to $400 \mathrm{~cm}^{-1}$. The solid samples were detected after mixing with dry $\mathrm{KBr}$.

Nitrogen sorption isotherms of the supports and catalysts were detected by a Micromeritics TriStar II 2020 porosimetry analyzer at $77 \mathrm{~K}$. Using the Brunauer-Emmett-Teller (BET) method, the specific surface areas of the samples were calculated. The total volumes of mesopores and micropores were deduced from the amounts of nitrogen adsorbed at $P / P_{\mathrm{o}}=0.98$. According to the desorption branches of the isotherms using the Barrett-Joyner-Halenda (BJH) method, the distribution of pore size was obtained.

Scanning electron microscopy (SEM) images of the samples were recorded with a Cambridge S-360 apparatus operating at $20 \mathrm{kV}$. Transmission electron microscopy (TEM) images were detected using a JEOL JEM 2100 electron microscope operated at an accelerating voltage of $200 \mathrm{kV}$. The samples were grinded in an agate mortar and suspended in ethanol with ultrasonic. Several drops of the supernatant liquid were dripped on a copper grid coated with a sputtered carbon polymer.

The amounts and types of the acids on the surface of the samples were analyzed by a pyridine-FTIR (Py-FTIR) spectroscopy on a MAGNAIR 560 FTIR instrument with a resolution of $1 \mathrm{~cm}^{-1}$. The samples were dehydrated at $873 \mathrm{~K}$ for $5 \mathrm{~h}$ under a vacuum of 1.33 of $10^{-3} \mathrm{~Pa}$, and then adsorbed of the purified pyridine vapor at room temperature for $20 \mathrm{~min}$. The IR spectra were recorded after the system was degassed and evacuated at different temperatures.

With a UV-Vis spectrophotometer (Hitachi U-4100) equipped with the integration sphere diffuse reflectance attachment, the
UV-Vis diffuse reflectance spectroscopy (UV-Vis DRS) was detected in the wavelength range of 200-800 $\mathrm{nm}$.

Raman spectra were recorded using a Renishaw MicroRaman System 2000 spectrometer with spectral resolution of $2 \mathrm{~cm}^{-1}$. The $325 \mathrm{~nm}$ line from a He/Cd laser was to be the exciting source with an output of $200 \mathrm{~mW}$. The Raman spectra between $200 \mathrm{~cm}^{-1}$ and $1200 \mathrm{~cm}^{-1}$ were automatically recorded at room temperature with the condition of $50 \mathrm{~s}$ accumulation at a $1 \mathrm{~cm}^{-1}$ resolution.

The X-ray photoelectron spectra (XPS) of the sulfided catalysts were tested in a Thermo Fisher K-Alpha spectrometer using $\mathrm{Al} \mathrm{K \alpha}$. All the obtained data were calibrated by taking the $\mathrm{C} 1 \mathrm{~s}$ spectrum (binding energy $=284.6 \mathrm{eV}$ ) as a standard.

\subsection{Catalytic activity measurement}

The catalytic performances of all the catalysts $(0.5 \mathrm{~g}, 40-60$ mesh) were studied with using DBT as the probe molecule in a continuous flowing tubular fixed-bed reactor $(8 \mathrm{~mm}$ inner diameter and $400 \mathrm{~mm}$ in length). In order to improve catalytic activity, all the catalysts needed to be presulfided for $4 \mathrm{~h}$ with $\mathrm{H}_{2}$ and $2 \mathrm{wt} \% \mathrm{CS}_{2}$ dissolved in cyclohexane at $613 \mathrm{~K}$ and $4 \mathrm{MPa}$. After the above operation, the HDS reaction of DBT was carried out under the conditions of $613 \mathrm{~K}, 4 \mathrm{MPa}, 200 \mathrm{ml} \mathrm{ml}^{-1}\left(\mathrm{H}_{2}\right)$ hydrocarbon) and different WHSV of $20-150 \mathrm{~h}^{-1}$. The sulfur contents of the feed and products were gauged with a sulfur and nitrogen analyzer (RPP-2000SN, Taizhou Central Analytical Instruments Co. Ltd., P. R. China). The catalytic performances (HDS efficiency (\%)) of the catalysts were calculated by eqn (1):

$$
\operatorname{HDS}(\%)=\left(\mathrm{S}_{\mathrm{f}}-\mathrm{S}_{\mathrm{p}}\right) / \mathrm{S}_{\mathrm{f}} \times 100 \%
$$

where the $S_{f}$ stands for the sulfur content of the feed, and $S_{p}$ represents the sulfur content of the products.

\section{Results}

\subsection{SAXS characterization of the supports}

SAXS characterization results of all the materials are shown in Fig. 1. As can be seen from the patterns, six diffraction peaks existing in the pure FDU-12, belonged to different lattice planes, including (111), (220), (311), (331), (333), and (442). ${ }^{30}$ And Zr-F

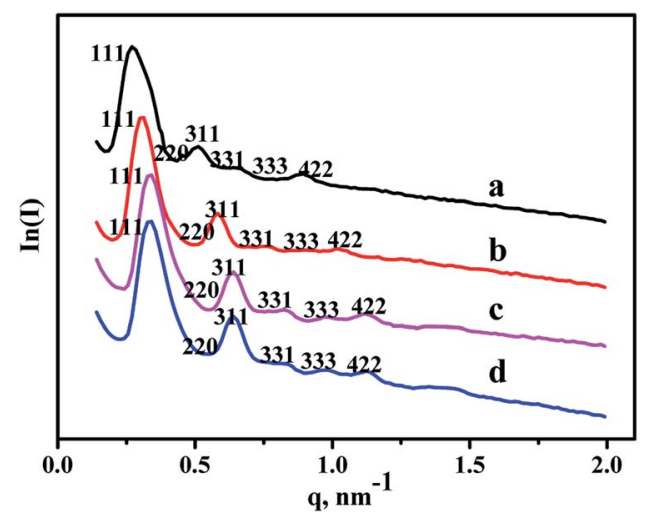

Fig. 1 SAXS patterns of the as-synthesized materials: (a) FDU-12, (b) Zr-in-F, (c) Zr-gra-F, (d) Zr-im-F. 

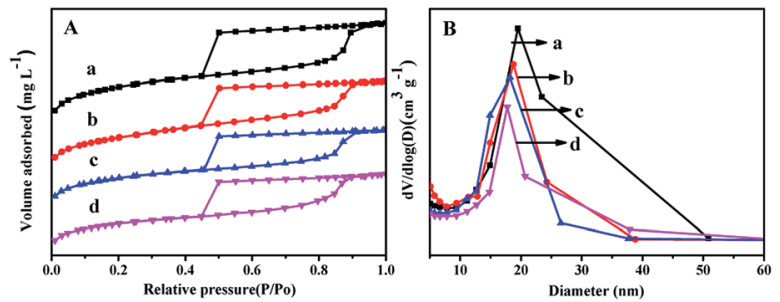

Fig. $2 \mathrm{~N}_{2}$ adsorption-desorption isotherms (A) and pore size distributions (B) of the as-synthesized materials: (a) FDU-12, (b) Zr-in-F, (c) Zr-gra-F, (d) Zr-im-F.

materials obtained by three different synthesis methods display the same diffraction peaks, illustrating that all the modified materials retain cubic $F m 3 m$ structure very well even after the incorporation of Zr. Furthermore, the intensities of all the diffraction peaks are relatively obvious indicating that all assynthesized materials have better crystallinities after the modification of Zr. In addition, the peaks positions shift toward high angle, indicating the decrease of pore sizes after the incorporation of $\mathrm{Zr}$ species, and this was confirmed by the following $\mathrm{N}_{2}$ adsorption characterization.

\section{2 $\quad \mathrm{N}_{2}$ adsorption-desorption characterization of the supports}

Fig. 2 displays the $\mathrm{N}_{2}$ adsorption-desorption isotherms and pore distribution of all the as-synthesized supports. From Fig. 2A, it can be seen that all the supports show the type IV of line with a $\mathrm{H} 2$ hysteresis loop in the range of $P / P_{\mathrm{o}}=0.45-0.93$, which indicates that all the synthesized materials can keep mesoporous characteristics. ${ }^{27}$ And the sharp decrease in the range of $P / P_{\mathrm{o}}=0.40-0.50$ displays that all the materials have a relatively uniform mesopores.

It can be seen from Fig. 2B that Zr-F materials obtained by different methods show a more centralized pore distribution compared with the pure FDU-12 material. Furthermore, the pore diameters of all the materials keep the order: FDU-12 $>\mathrm{Zr}-$ in-F $>$ Zr-gra-F $>$ Zr-im-F. Textural structure parameters of the pure FDU-12 and Zr-F materials are listed in Table 1. It can be formed that the pure FDU-12 have the highest specific surface area $\left(789 \mathrm{~m}^{2} \mathrm{~g}^{-1}\right)$ and the pore volume $\left(0.72 \mathrm{~cm}^{3} \mathrm{~g}^{-1}\right)$ among all the as-synthesized materials. Furthermore Zr-in-F have the higher specific surface area and the pore volume than $\mathrm{Zr}$-gra-F and $\mathrm{Zr}-\mathrm{im}-\mathrm{F} .{ }^{31}$ It might be attributed to the fact that $\mathrm{Zr}$ source added in the process of post synthesis cannot be efficiently assembled into the mesoporous FDU-12 framework. After calcination, the formation of $\mathrm{ZrO}_{2}$ microcrystal particles resulted in the channel blockage. Thereafter, the deduction is confirmed by the characterization result of UV-Vis. Furthermore, the contents of $\mathrm{ZrO}_{2}$ in the supports detected by XRF characterization follows the order: Zr-im-F $>$ Zr-in-F $>$ Zr-gra-F.

\subsection{SEM characterization of the supports}

The morphologies of $\mathrm{Zr}-\mathrm{F}$ mesoporous materials obtained by different methods are studied by SEM. It can be seen from Fig. 3 that all the synthesized Zr-F materials prepared through three different modification methods exhibit relatively regular hexagonal prims, which indicate that the morphologies of the mesoporous FDU-12 were retained after the incorporation of $\mathrm{Zr}$ species. Furthermore, the particle diameter of $\mathrm{Zr}-\mathrm{in}-\mathrm{F}$ is slightly less than that of Zr-im-F and Zr-gra-F.

\subsection{TEM characterization of the supports}

In order to analyze the mesoporous channels of the as-synthesized supports, all the as-synthesized materials are characterized by TEM technique, and the results are displayed in Fig. S1. $\dagger$ From those pictures, it can be seen that Zr-im-F and Zr-gra-F materials obtained by the post synthesized methods can keep the orderly pore structures, belonging to the typical cubic $F m 3 m$ topology of FDU12. However, the pore structure of Zr-F material obtained by the direct synthesis method is slightly orderless comparing with those of the post synthesis. It is because the radiuses and coordination numbers of zirconium and silicon atoms are different. Thus when the silicon atoms in the framework are partially replaced by zirconium, the skeleton might be slightly twisted, leading to the decrease of the order degree.

\subsection{FTIR characterization of the supports}

The characterization of FTIR is performed to analyze the existence state of $\mathrm{Zr}$ species in the supports. FTIR spectra of FDU-12, Zr-in-F, Zr-im-F and Zr-gra-F supports are displayed in Fig. 4. It can be seen from the pictures that the pure FDU-12 support shows strong bands at 460 and $805 \mathrm{~cm}^{-1}$, which are attributed to the bending and symmetric vibration of $\mathrm{Si}-\mathrm{O}-\mathrm{Si}^{\mathrm{3} 2,33}$ However, the band at $805 \mathrm{~cm}^{-1}$ shifted to $820 \mathrm{~cm}^{-1}$ for all the modified materials, which is attributed to the incorporation of $\mathrm{Zr}$ species, modulating the chemical environment of Si species. The band at $1025 \mathrm{~cm}^{-1}$ is the band associated with asymmetric stretching vibration of $\mathrm{Si}-\mathrm{O}-\mathrm{Si}$ bond. ${ }^{34}$ The pure FDU-12 material exhibits a band at $950 \mathrm{~cm}^{-1}$, which is assigned to $\mathrm{Si}-\mathrm{OH} ;{ }^{35}$ however, the band shifts to $960 \mathrm{~cm}^{-1}$ for all the $\mathrm{Zr}-\mathrm{F}$ materials.

Table 1 Textural structure parameters of the as-synthesized materials

\begin{tabular}{lllll}
\hline Samples & BET surface area ${ }^{a}\left(\mathrm{~m}^{2} \mathrm{~g}^{-1}\right)$ & Total pore volume ${ }^{b}\left(\mathrm{~cm}^{3} \mathrm{~g}^{-1}\right)$ & Pore diameter $^{c}(\mathrm{~nm})$ & ${\text { Contents of } \mathrm{ZrO}_{2}{ }^{\mathrm{d}}, m^{\circ}}$ \\
\hline FDU-12 & 785 & 0.72 & 19.5 & 8.9 \\
Zr-in-F & 709 & 0.65 & 18.7 & 7.6 \\
Zr-gra-F & 664 & 0.55 & 18.2 & 9.1 \\
Zr-im-F & 647 & 0.54 & 17.8 & 9.1
\end{tabular}

${ }^{a}$ Calculated by BET method. ${ }^{b}$ Obtained at a relatively pressure of $0.98 .{ }^{c}$ Calculated using BJH method. ${ }^{d}$ Measured by the XRF characterization. 


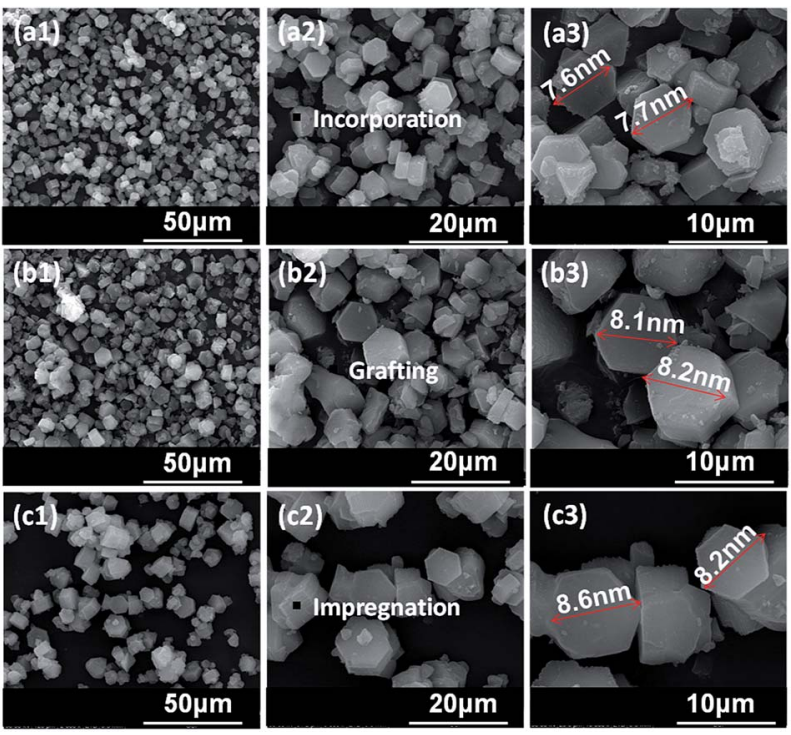

Fig. 3 SEM images of FDU-12 series materials with different $\mathrm{Zr}$ modification methods: (a) Zr-in-F, (b) Zr-gra-F, (c) Zr-im-F, 1-3 represent different scales.

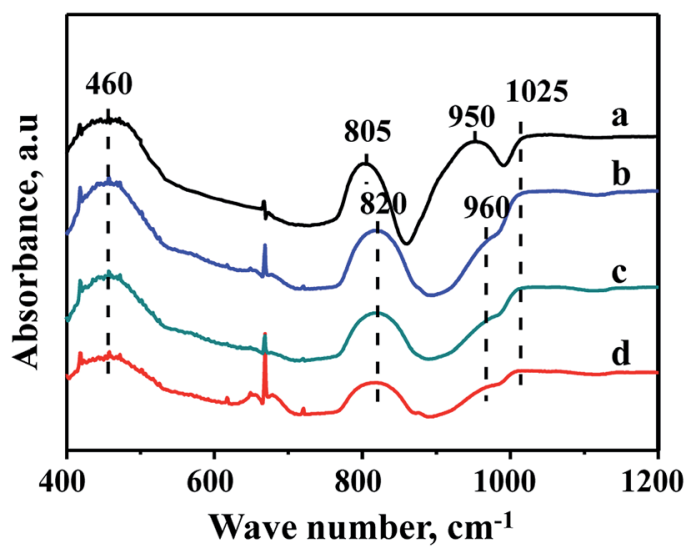

Fig. 4 FT-IR patterns of FDU-12 series materials with different $Z r$ modification methods: (a) FDU-12, (b) Zr-in-F, (c) Zr-gra-F, (d) Zr-im-F.

And the band is ascribed to the synergistic effect of the $\mathrm{Si}-\mathrm{OH}$ and $\mathrm{Si}-\mathrm{O}-\mathrm{Zr}$ groups, ${ }^{35}$ suggesting $\mathrm{Zr}$ species are incorporated into the framework of all the modified materials.

\subsection{UV-Vis characterization of the supports}

Due to the different chemical environment of the metallic species over the support, there are different coordination states for the metals, thus different absorption peaks can be observed in the UV-Vis characterization. Therefore, UV-Vis spectroscopy is widely used to characterize the modified mesoporous materials. Fig. 5 shows UV-Vis spectra of various species involving $\mathrm{ZrO}_{2}$, $\mathrm{Zr}$ source $\left(\mathrm{ZrOCl}_{2} \cdot 8 \mathrm{H}_{2} \mathrm{O}\right)$, pure FDU-12 and $\mathrm{Zr}-\mathrm{F}$ materials obtained by three different methods. It can be seen from Fig. 6 that all the modified FDU-12 materials have an obvious absorption peak at $205 \mathrm{~nm}$ in contrast with the pure FDU-12 material. According to the literature, ${ }^{36,37}$ the peak is assigned to the electron transition phenomenon from $\mathrm{p}$ orbit to $\mathrm{d}$ orbit

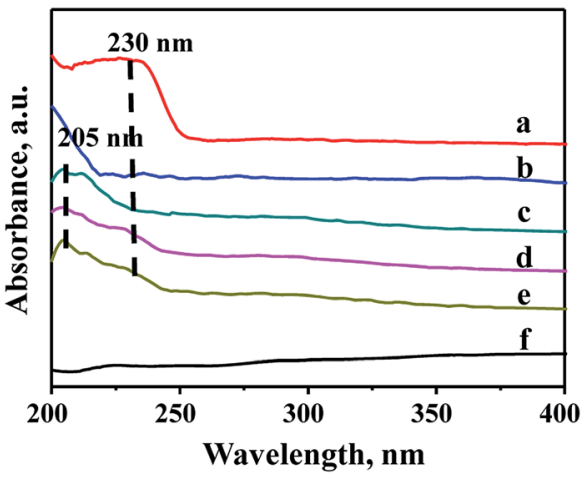

Fig. 5 UV-Vis DRS spectra of FDU-12 series materials with different $\mathrm{Zr}$ modification methods: (a) $\mathrm{ZrO}_{2}$, (b) $\mathrm{ZrOCl}_{2} \cdot 8 \mathrm{H}_{2} \mathrm{O}$, (c) $\mathrm{Zr}$-in-F, (d) $\mathrm{Zr}$ gra-F, (e) Zr-im-F, (f) FDU-12.

$(\mathrm{O} \rightarrow \mathrm{Zr})$ in the skeleton, which further confirms that most of $\mathrm{Zr}$ species have been incorporated into the framework successfully. Meanwhile, similar to $\mathrm{ZrO}_{2}$ spectra, $\mathrm{Zr}$-im-F and Zr-gra-F also show a weak peak at $230 \mathrm{~nm}$, which implies the existence of $\mathrm{ZrO}_{2} \cdot{ }^{36}$ It is derived from the non-framework $\mathrm{Zr}$ species, which are existed as the separated phases, and absorbed on the surface of mesoporous FDU-12, then easy to transform into $\mathrm{ZrO}_{2}$ particles after calcination. Furthermore, the sample of $\mathrm{Zr}$ in-F does not display the peak at $230 \mathrm{~nm}$ corresponding to $\mathrm{ZrO}_{2}$ bulk phases, suggested that no isolated $\mathrm{ZrO}_{2}$ species are formed over the support. And it can be inferred that most of the $\mathrm{Zr}$ species have been successfully embedded into the skeleton of mesoporous FDU-12. Combining with XRF analysis, it can also be concluded that $\mathrm{Zr}$-in-F material prepared by the directsynthesis method incorporates more $\mathrm{Zr}$ species into the framework than those prepared by the post-synthesis methods.

\subsection{BET characterization of the catalyst}

$\mathrm{N}_{2}$ adsorption-desorption isothermal and pore distribution of NiMo/FDU-12 and NiMo/Zr-F catalysts obtained by different modified methods are shown in Fig. 6. From Fig. 6A it can be found that all the prepared catalysts display the type IV isothermals with type $\mathrm{H} 2$ hysteresis loops, which confirm that the mesoporous texture of different materials are well maintained after impregnating active metals. It is found from Fig. 6B that all the catalysts show relatively uniform aperture distribution, and the most probable aperture of all the catalysts keep the order: NiMo/ FDU-12 > NiMo/Zr-in-F > NiMo/Zr-gra-F > NiMo/Zr-im-F. The pore textures of different catalysts are summarized in Table 2.
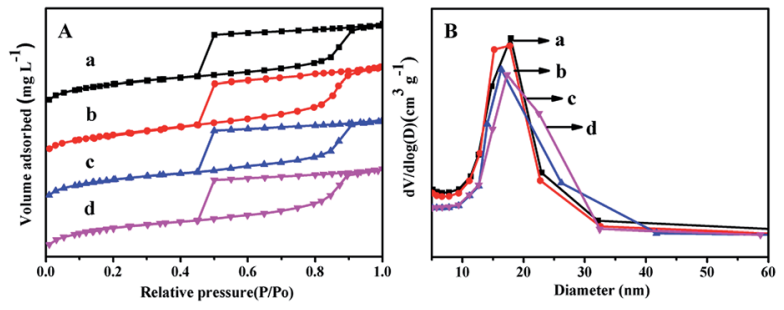

Fig. $6 \mathrm{~N}_{2}$ adsorption-desorption isotherms (A) and pore distribution (B) of the catalysts: (a) NiMo/FDU-12, (b) NiMo/Zr-in-F, (c) NiMo/Zrgra-F, (d) NiMo/Zr-im-F. 
Table 2 Textural properties of the catalysts with different prepared methods

\begin{tabular}{llll}
\hline Samples & $S_{\mathrm{BET}}{ }^{a}\left(\mathrm{~m}^{2} \mathrm{~g}^{-1}\right)$ & $V_{\mathrm{t}}^{b}\left(\mathrm{~cm}^{3} \mathrm{~g}^{-1}\right)$ & $d_{\mathrm{BJH}}{ }^{c}(\mathrm{~nm})$ \\
\hline NiMo/FDU-12 & 391 & 0.59 & 18.6 \\
NiMo/Zr-in-F & 373 & 0.43 & 17.8 \\
NiMo/Zr-gra-F & 358 & 0.39 & 17.2 \\
NiMo/Zr-im-F & 332 & 0.39 & 17.1
\end{tabular}

${ }^{a}$ Calculated by BET method. ${ }^{b}$ Obtained at a relatively pressure of 0.98 . ${ }^{c}$ Calculated using BJH method.

Comparing to the corresponding support materials, the specific surface area, volume and pore diameter of the catalysts slightly decrease, which are attributed to the loadings of active metals occupying some support surfaces or blocking channels. ${ }^{\mathbf{1 6}}$

\subsection{UV-Vis of the oxide catalysts}

UV-Vis spectra is performed to analyze the distribution of Mo species in different catalysts, and the results are exhibited in Fig. S2. $\dagger$ It is obvious from Fig. $\mathrm{S} 2 \dagger$ that all the catalysts obtained by different methods show absorption bands at 200$400 \mathrm{~nm}$, which are assigned to different coordination Mo oxide species. The band at $220-250 \mathrm{~nm}$ is ascribed to the isolated tetrahedral coordination species, ${ }^{38,39}$ and the band at 250 $350 \mathrm{~nm}$ is ascribed to the octahedral coordination species. ${ }^{39}$ Furthermore, there are no absorption bands attributing to the isolated $\mathrm{MoO}_{3}$ species, which confirms that Mo species are well dispersed on the supports.

\subsection{Raman of the oxide catalyst}

In order to analyze the crystalline symmetry and the nature of the oxide phases, all the catalysts are characterized by Raman spectra, ${ }^{\mathbf{4 0 , 4 1}}$ and the results are displayed in Fig. 7. For the prepared catalysts, there are some characteristic bands at $364 \mathrm{~cm}^{-1}$, $750 \mathrm{~cm}^{-1}, 847 \mathrm{~cm}^{-1}$, and $940 \mathrm{~cm}^{-1}$ observed in Fig. 8. All the $\mathrm{NiMo} / \mathrm{Zr}-\mathrm{F}$ catalysts exhibit a band at $750 \mathrm{~cm}^{-1}$ assigning to bulk $\mathrm{Zr}\left(\mathrm{MoO}_{4}\right)$, which is derived from the stretching vibration of $\mathrm{Zr}-\mathrm{O}-$ Mo. ${ }^{42}$ Furthermore, the band at $364 \mathrm{~cm}^{-1}$ and $847 \mathrm{~cm}^{-1}$ are assigned to bending vibration of $\mathrm{Mo}=\mathrm{O}$ in tetrahedrally coordinated molybdate $\left(\mathrm{MoO}_{4}{ }^{2-}\right)$, and the band at $940 \mathrm{~cm}^{-1}$ is ascribed

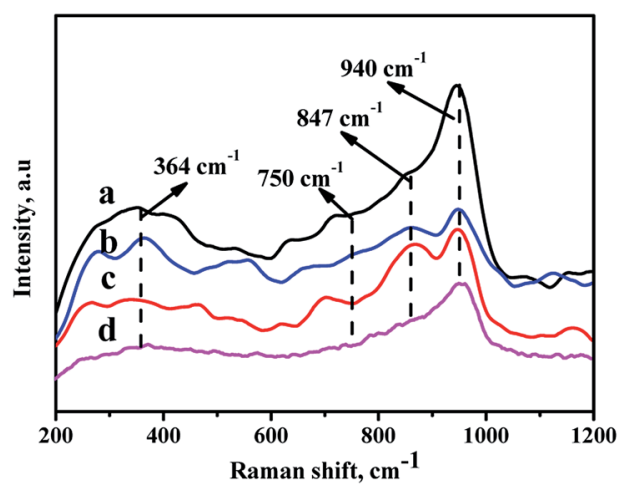

Fig. 7 Raman spectra of the catalysts with different prepared methods: (a) NiMo/Zr-in-F, (b) NiMo/Zr-gra-F, (c) NiMo/Zr-im-F, (d) $\mathrm{NiMo} / \mathrm{FDU}-12$.
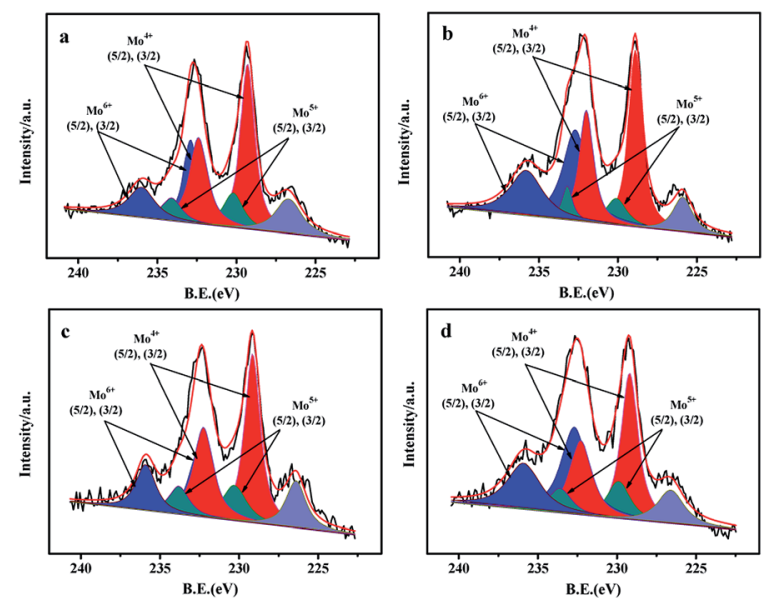

Fig. 8 Mo 3d XPS spectra of the sulfided catalysts with different prepared methods: (a) NiMo/Zr-in-F, (b) NiMo/Zr-gra-F, (c) NiMo/Zrim-F, (d) NiMo/FDU-12.

to the stretching vibration of $\mathrm{Mo}=\mathrm{O}$ in the octahedrally coordinated polymolybdate $\left(\mathrm{Mo}_{7} \mathrm{O}_{24}{ }^{6-}\right),{ }^{43,44}$ which is formed due to the weak interaction between the active metals and the supports, easy to be reduced and sulfurized, resulting in high activity of hydrodesulfurization reaction. For all the modified catalysts, the intensities of bands here are in the following order: NiMo/Zr-in-F > NiMo/Zr-im-F > NiMo/Zr-gra-F. Furthermore, the catalyst NiMo/ Zr-in-F does not show some bands at $289 \mathrm{~cm}^{-1}, 818 \mathrm{~cm}^{-1}$ and $994 \mathrm{~cm}^{-1}$ assigned to vibration of $\mathrm{Mo}=\mathrm{O}$ in $\mathrm{MoO}_{3},{ }^{45}$ indicating that Mo species are highly dispersed on the surface of this catalyst.

\subsection{XPS of the sulfided catalysts}

XPS characterization is performed to obtain the information about the contents of various compounds ( $\mathrm{Zr}, \mathrm{Mo})$ as well as the sulfidation degree of Mo species. The $\mathrm{O} 1 \mathrm{~s}$ spectrums of the $\mathrm{O}$ element in NiMo/Zr-F catalysts obtained by different synthesis methods are presented in Fig. S3. $\uparrow$ The vibration peaks at 532.9 and $532 \mathrm{eV}$ are respectively attributed to the $\mathrm{Si}-\mathrm{O}-\mathrm{Si}$ bridge and the $\mathrm{Si}-\mathrm{OH}$ bridge on the catalysts. ${ }^{21}$ Additionally, the less intensified peak centered at $53.09 \mathrm{eV}$ is assigned to the vibration of the $\mathrm{Si}-\mathrm{O}-\mathrm{Zr}$, indicating the presence of $\mathrm{Zr}$ species in the framework of FDU-12 materials. $^{28}$

The Mo 3d XPS spectrums of the sulfided catalysts are performed to analyze the sulfidation degrees of Mo active species. ${ }^{21}$ From Fig. 8, the spectra of Mo 3d are decomposed into three contributions, which are $\mathrm{Mo}^{4+}, \mathrm{Mo}^{5+}$, and $\mathrm{Mo}^{6+}$ respectively. For all the catalysts, the high intensified peaks at $229.3 \mathrm{eV}$ and $232.4 \mathrm{eV}$, which have a fixed intensity ratio of $3: 2,{ }^{21,29,30}$ are attributed to the $\mathrm{Mo}^{4+} 3 \mathrm{~d}_{3 / 2}$ and $3 \mathrm{~d}_{5 / 2}$, proving the formation of $\mathrm{MoS}_{2}$ species. The relatively high intensified peaks at $232.9 \mathrm{eV}$ and $236.0 \mathrm{eV}$ are assigned to $\mathrm{Mo}^{6+} 3 \mathrm{~d}_{3 / 2}$ and $3 \mathrm{~d}_{5 / 2}$, indicating that partial Mo species in oxidation states still exist on the surface of the catalysts after the sulfidation. Furthermore, the peaks of $\mathrm{Mo}^{5+} 3 \mathrm{~d}_{3 / 2}$ and $3 \mathrm{~d}_{5 / 2}$ with low intensities can be also observed at $230.2 \mathrm{eV}$ and $233.5 \mathrm{eV}$. The bond centered at $226.7 \mathrm{eV}$ is attributed to $\mathrm{S}_{2 \mathrm{~S}}$. 
Table 3 XPS fitting results of Mo 3d spectra of the sulfide catalysts with different modified methods

\begin{tabular}{|c|c|c|c|c|c|c|c|}
\hline Catalysts & \multicolumn{2}{|l|}{$\mathrm{Mo}^{4+}$} & \multicolumn{2}{|l|}{$\mathrm{Mo}^{5+}$} & \multicolumn{2}{|l|}{$\mathrm{Mo}^{6+}$} & $S_{\mathrm{Mo}}{ }^{b}, \%$ \\
\hline NiMo/Zr-in-F & 33.5 & 22.9 & 10.1 & 6.8 & 16.0 & 10.7 & 56.4 \\
\hline NiMo/Zr-gra-F & 29.5 & 19.7 & 7.4 & 4.3 & 23.6 & 16.0 & 49.5 \\
\hline NiMo/Zr-im-F & 32.8 & 21.9 & 10.3 & 6.9 & 16.9 & 11.2 & 54.7 \\
\hline
\end{tabular}

The results obtained by the deconvolution method $^{30}$ are summarized in Table 3. The sulfidation degree of Mo active species can be evaluated by using the proportion of $\mathrm{Mo}^{4+}$ phases in the total Mo species, while the $\mathrm{Mo}^{4+} /\left(\mathrm{Mo}^{4+}+\mathrm{Mo}^{5+}+\mathrm{Mo}^{6+}\right)$ is defined as the values of $\mathrm{Mo}_{\text {sulfidation }} / \mathrm{Mo}_{\text {total }}$. The sulfidation degree of all the catalysts keeps the order: NiMo/Zr-in-F(56.4\%) > NiMo/Zr-im$\mathrm{F}(54.7 \%)>\mathrm{NiMo} / \mathrm{Zr}$-gra-F $(49.5 \%)>\mathrm{NiMo} / \mathrm{FDU}-12(45.5 \%)$, which is in agreement with the activity results of the catalysts. Finally, the XPS results demonstrate that the Mo species over the catalyst obtained by the direct synthesis are sulfided easily than those over the catalysts obtained by the post synthesis.

\subsection{Py-IR of catalysts}

Due to the different sizes and coordination numbers of $\mathrm{Zr}$ and $\mathrm{Si}$ atoms, the introduction of $\mathrm{Zr}$ species into the skeleton of mesoporous silica produces electric unsaturation of $\mathrm{Zr}-\mathrm{O}-\mathrm{Si}$, leading to the generation of acid sites, including Lewis and Brønsted acid sites. ${ }^{21}$ Pyridine-FTIR spectra are used to analyze the strength and types of acid sites of all the catalysts by different prepared methods. The adsorption pyridines are mainly degassed at 200 and $350{ }^{\circ} \mathrm{C}$ : the low temperature desorption at $200{ }^{\circ} \mathrm{C}$ is assigned to the total amounts of acid sites, while the high temperature desorption at $350{ }^{\circ} \mathrm{C}$ is associated with the medium and strong acid sites. Different bands can be exhibited in the wavelength of $1700-1400 \mathrm{~cm}^{-1}$ in the spectra as shown in Fig. 9. The bands at $1450 \mathrm{~cm}^{-1}$ and $1610 \mathrm{~cm}^{-1}$ are assigned to Lewis acid sites; and the bands at $1540 \mathrm{~cm}^{-1}$ and $1650 \mathrm{~cm}^{-1}$ are ascribed to the Brønsted acid sites, while the band at $1492 \mathrm{~cm}^{-1}$ is attributed to a combination of Brønsted and Lewis acid sites. ${ }^{\mathbf{4 6 , 4 7}}$

The detailed data about the acid strength distribution and acid quantity of all the catalysts calculated from the pyridineFTIR spectra are listed in Table S1. $\dagger$ It can be seen from the
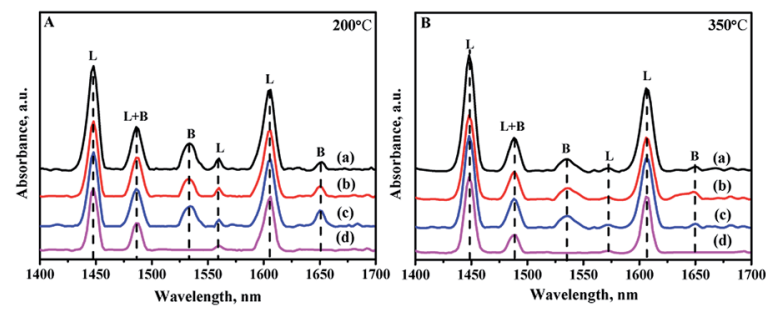

Fig. 9 FTIR spectra of pyridine adsorbed on different catalysts after degassing at (A) $200{ }^{\circ} \mathrm{C}$ and (B) $350{ }^{\circ} \mathrm{C}$ : (a) NiMo/Zr-in-F, (b) NiMo/Zrgra-F, (c) NiMo/Zr-im-F.
Table $\mathrm{S} 1 \dagger$ that the NiMo/FDU-12 catalyst only show the existence of Lewis acid sites, and all the modified catalysts show the existence of Brønsted and Lewis acid sites, including the weak and strong acid sites. The acidities of the catalysts are associated with the incorporated quantity of $\mathrm{Zr}$, and the acidities increase as the incorporation amount of $\mathrm{Zr}$ increases in a reasonable range of $\mathrm{Zr}$ species addition. ${ }^{48}$ The total acid amounts of all the catalysts measured at 200 and $350{ }^{\circ} \mathrm{C}$ follow the order: NiMo/Zr-in-F > NiMo/Zr-im-F > NiMo/Zr-gra-F > NiMo/FDU-12, which is in consistent with the loading of $\mathrm{Zr}$ species incorporated into the skeleton. This is the same to the characterization results of UV-Vis and XRF.

\subsection{Catalytic activity}

The HDS activity of all the catalysts obtained by different prepared methods are evaluated using DBT (500 ppm of S, wt\%) as the feedstock, and the results are shown in Fig. 10. From Fig. 10, it can be seen that the HDS performances of all the catalysts gradually increase with the WHSV values decreasing. Comparing with the NiMo/FDU-12 catalyst, the NiMo/Zr-F catalysts obtained by different synthesis routes exhibit better catalytic activities, which are attributed to higher dispersion of Mo species and more acid sites as a result of the incorporation of $\mathrm{Zr}$ species. The NiMo/Zr-in-F and NiMo/Zr-im-F catalysts show better catalytic activities than $\mathrm{NiMo} / \mathrm{Al}_{2} \mathrm{O}_{3}$.

Among all the prepared catalysts, the NiMo/Zr-in-F catalyst show the best performance, and presents the highest DBT HDS

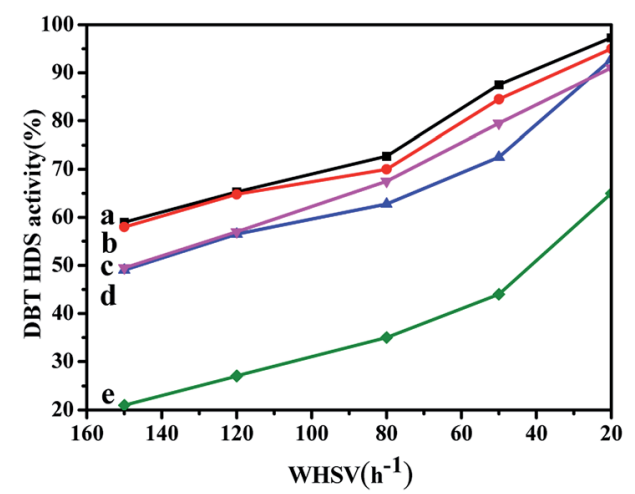

Fig. 10 DBT HDS performance over series of catalysts with various prepared methods at different WHSV values $(613 \mathrm{~K}, 4 \mathrm{MPa} .200 \mathrm{ml}$ $\mathrm{ml}^{-1}$ ): (a) $\mathrm{NiMo} / \mathrm{Zr}-\mathrm{in}-\mathrm{F}$, (b) $\mathrm{NiMo} / \mathrm{Zr}-\mathrm{im}-\mathrm{F}$, (c) $\mathrm{NiMo} / \mathrm{Al}_{2} \mathrm{O}_{3}$, (d) $\mathrm{NiMo} /$ Zr-gra-F, (e) NiMo/FDU-12. 
efficiency of $97.3 \%$ at the WHSV value of $20 \mathrm{~h}^{-1}$. The explanation can be derived from the following reasons: firstly, the $\mathrm{N}_{2}$ adsorption and desorption characterizations suggested that $\mathrm{Zr}$ in-F had the higher specific surface area $\left(785 \mathrm{~m}^{2} \mathrm{~g}^{-1}\right)$ comparing with the catalysts obtained by the post synthesis methods, which indicates that it can provide enough spaces for the dispersion of active sites. Moreover, the larger pore size and volume of the Zr-in-F support allowed DBT and the product molecules to diffuse rapidly in the channels. Secondly, according to the UV-Vis and Raman spectra, the Ni and Mo species were well dispersed over the NiMo/Zr-in-F catalyst, and the higher proportion of highly active multiple coordination polymolybdate species were observed over the NiMo/Zr-in-F catalyst in Fig. 7, which facilitated to increase the HDS performance. Furthermore, the catalyst NiMo/Zr-in-F had the most sulfided molybdenum species as shown in Table 3 compared with the other catalysts. Finally, the NiMo/Zr-in-F catalyst possessed more acid sites from the data in Table $\mathrm{S} 1, \dagger$ which would be advantage to break the $\mathrm{C}-\mathrm{S}$ bond and transfer alkyl groups. The performances of all the prepared catalysts kept the following order: NiMo/Zr-in-F > NiMo/Zr-im-F $>\mathrm{NiMo} / \mathrm{Al}_{2} \mathrm{O}_{3}>\mathrm{NiMo} / \mathrm{Zr}-$ gra-F $>$ NiMo/FDU-12. For the NiMo/Zr-gra-F catalyst, although it had larger specific surface area and pore size, the less acid sites and the sulfided degree restricted the HDS reaction. Thus, NiMo/Zr-gra-F exhibited a lower catalytic activity than that of $\mathrm{NiMo} / \mathrm{Zr}-\mathrm{im}-\mathrm{F}$. In conclusion, the NiMo/Zr-in-F catalyst with higher specific surface, pore volume, pore size, and more acid sites, displayed the highest DBT HDS performance.

\section{Conclusions}

A series of Zr-FDU-12 materials were synthesized by three different methods, including the direct synthesis and post synthesis (grafting and impregnating) routes, and the corresponding catalysts were prepared by impregnation with Mo and $\mathrm{Ni}$ active metals. Then the materials and catalysts were characterized well via different techniques, i.e. the SAXS, Py-IR and XPS. According to the results of SAXS and TEM analysis, all the modified materials maintained a relatively ordered mesoporous structures after the incorporation of $\mathrm{Zr}$. The $\mathrm{N}_{2}$ adsorption and desorption results showed that the $\mathrm{Zr}$-in-F material obtained by the direct synthesis method possessed the largest specific surface area $\left(709 \mathrm{~m}^{2} \mathrm{~g}^{-1}\right)$, volume $\left(0.65 \mathrm{~cm}^{3} \mathrm{~g}^{-1}\right)$ and pore size $(18.7 \mathrm{~nm})$ in contrast with the Zr-im-F and Zr-gra-F materials. Meanwhile combining with the FT-IR and UV-Vis characterizations, $\mathrm{Zr}$ species were well incorporated into the framework of Zr-in-F material comparing with Zr-gra-F and Zr-im-F materials. Furthermore, based on the Raman and UV-Vis characterization results, it could be found that all the modified catalysts had better dispersion of Mo active phases. The catalytic performances of all the catalysts were evaluated in hydrodesulfurization using DBT as the feedstock, which demonstrated that the catalyst NiMo/Zr-in-F had the highest DBT HDS activity among all the prepared catalysts. It could be deduced that the good catalytic performance of NiMo/Zr-in-F was ascribed to the synergistic influence of its larger specific area $\left(373 \mathrm{~m}^{2} \mathrm{~g}^{-1}\right)$, pore volume $\left(0.43 \mathrm{~cm}^{3} \mathrm{~g}^{-1}\right)$, pore size $(17.8$ $\mathrm{nm}$ ), and more acid sites (104.8 $\left.\mathrm{mmol} \mathrm{g}^{-1}\right)$, which conform it a more potential catalyst for HDS process.

\section{Conflicts of interest}

No conflict of interest exists in the submission of this manuscript, and the manuscript is approved by all authors for publication.

\section{Acknowledgements}

This work was financially supported by the National Natural Science Foundation of China (No. 21676298, U1463207 and 21503152), CNPC Key Research Project and KLGCP (GCP201401).

\section{References}

1 S. T. Oyama, H. Y. Zhao, H. J. Freund, K. Asakura, R. Włodarczyk and M. Sierka, J. Catal., 2012, 1, 1-5.

2 D. Q. Zhang, A. J. Duan, Z. Zhao and C. M. Xu, J. Catal., 2010, 2, 273-286.

3 C. S. Song and X. L. Ma, Appl. Catal., B, 2003, 1, 207-238.

4 P. Zheng, A. J. Duan, K. B. Chi, L. Zhao, C. Y. Zhang, C. M. Xu, Z. Zhao, W. Y. Song, X. L. Wang and J. Y. Fan, Chem. Eng. Sci., 2017, 164, 292-306.

5 F. Trejo, M. S. Rana and J. Ancheyta, Catal. Today, 2008, 2-4, 327-336.

6 F. Bataille, J. L. Lemberton, P. Michaud, G. Pérot, M. Vrinat, M. Lemaire, E. Schulz, M. Breysse and S. Kasztelan, J. Catal., 2000, 2, 409-422.

7 Y. Fan, G. Shi, H. Liu and X. J. Bao, Appl. Catal., B, 2009, 1-2, 73-82.

8 A. Röthlisberger and R. Prins, J. Catal., 2005, 1, 229-240.

9 A. Romero-Galarza, A. Gutiérrez-Alejandre and J. Ramírez, J. Catal., 2011, 2, 230-238.

10 Y. Fan, J. Lu, G. Shi, H. Y. Liu and X. J. Bao, Catal. Today, 2007, 3, 220-228.

11 L. Kaluža and M. Zdražil, Appl. Catal., A, 2007, 329, 58-67.

12 Y. Ji, P. Afanasiev, M. Vrinat, W. Z. Li and C. Li, Appl. Catal., A, 2004, 2, 157-164.

13 M. J. Vissenberg, Y. van der Meer, E. J. M. Hensen, V. H. J. de Beer, A. M. van der Kraan, R. A. van Santen and J. A. R. van Veen, J. Catal., 2001, 2, 151-163.

14 L. Coulier, J. A. R. van Veen and J. W. Niemantsverdriet, Catal. Lett., 2002, 1, 149-155.

15 Z. K. Cao, X. Zhang, C. M. Xu, A. J. Daun, R. Guo, Z. Zhao, Z. M. Wu, C. Peng, J. M. Li, X. L. Wang and Q. Meng, Energy Fuels, 2016, 1, 805-814.

16 T. S. Li, A. J. Duan, Z. Zhao, B. J. Liu, G. Y. Jiang, J. Liu, Y. C. Wei and H. F. Pan, Fuel, 2014, 117, 974-980.

17 J. Liu, L. H. Yu, Z. Zhao, Y. S. Chen, P. Y. Zhu, C. Wang, Y. Luo, C. M. Xu, A. J. Duan and G. Y. Jiang, J. Catal., 2012, 1, 134-144.

18 K. Szczodrowski, B. Prélot, S. Lantenois, J. Douillard and J. Zajac, Microporous Mesoporous Mater., 2009, 1, 84-93. 
19 S. Y. Chen, L. Y. Jang and S. Cheng, Chem. Mater., 2004, 21, 4174-4180.

20 M. V. Landau, L. Titelman, L. Vradman and P. Wilson, Chem. Commun., 2003, 5, 594-595.

21 B. Wang, S. T. Song, L. N. Han, A. J. Duan, C. M. Xu, Z. T. Chen, Q. Meng, X. G. Chen, J. M. Li and D. Wang, Energy Fuels, 2017, 5, 5448-5460.

22 F. X. Li, Y. Feng, Y. l. Li, R. F. Li and K. C. Xie, Microporous Mesoporous Mater., 2007, 1, 250-255.

23 A. Olivas and T. A. Zepeda, Catal. Today, 2009, 1, 120-125.

24 P. Rayo, J. Ramírez, M. S. Rana, J. Ancheyta and A. AguilarElguézabal, Ind. Eng. Chem. Res., 2008, 3, 1242-1248.

25 T. Klimova, L. Peña, L. Lizama, C. Salcedo and O. Y. Gutiérrez, Ind. Eng. Chem. Res., 2008, 3, 1126-1133.

26 A. V. da Silva Neto, E. R. Leite, V. T. da Silva, L. Z. JoséErnesto and E. A. Urquieta-González, Appl. Catal., A, 2016, 528, 7485.

27 J. Fan, C. Z. Yu, F. Gao, J. Lei, B. Z. Tian, L. M. Wang, Q. Luo, B. Tu, W. Z. Zhou and D. Y. Zhao, Angew. Chem., Int. Ed., 2003, 27, 3254-3258.

28 Z. K. Cao, A. J. Duan, Z. Zhao, J. M. Li, Y. C. Wei, G. Y. Jiang and J. Liu, J. Mater. Chem. A, 2014, 46, 19738-19749.

29 X. L. Wang, P. Du, K. B. Chi, A. J. Duan, C. M. Xu, Z. Zhao, Z. T. Chen and H. L. Zhang, Catal. Today, 2017, 291, 146-152.

30 P. Du, P. Zheng, S. T. Song, X. L. Wang, M. H. Zhang, K. B. Chi, C. M. Xu, A. J. Duan and Z. Zhao, RSC Adv., 2016, 2, 1018-1026.

31 P. Biswas, P. Narayanasarma, C. M. Kotikalapudi, A. K. Dalai and J. Adjaye, Ind. Eng. Chem. Res., 2011, 13, 7882-7895.

32 M. G. Cazalilla, J. M. Mérida-Robles, A. Gurbani, E. Rodríguez-Castellón and A. Jiménez-López, J. Solid State Chem., 2007, 3, 1130-1140.

33 Y. Kuwahara, W. Kaburagi, K. Nemoto and T. Fujitani, Appl. Catal., A, 2014, 476, 186-196.
34 D. M. Do, S. Jaenicke and G. K. Chuah, Catal. Sci. Technol., 2012, 7, 1417-1424.

35 J. Y. Fu, P. Zheng, P. Du, A. J. Duan, Z. Zhao, G. Y. Jiang, J. Liu, Y. C. Wei, C. M. Xu and K. B. Chi, Appl. Catal., A, 2015, 502, 320-328.

36 K. Chaudhari, R. Bal, T. K. Das, A. Chandwadkar, D. Srinivas and S. Sivasanker, J. Phys. Chem. B, 2000, 47, 11066-11074.

37 M. S. Morey, G. D. Stucky, S. Schwarz and M. Fröba, J. Phys. Chem. B, 1999, 12, 2037-2041.

38 J. Ramírez, R. Contreras, P. Castillo, T. Klimova, R. Zárate and R. Luna, Appl. Catal., A, 2000, 1, 69-78.

39 T. Klimova, D. S. Casados and J. Ramírez, Catal. Today, 1998, 1, 135-146.

40 V. L. Parola, G. Deganello and A. M. Venezia, Appl. Catal., A, 2004, 2, 237-247.

41 J. A. Bergwerff, T. Visser and B. M. Weckhuysen, Catal. Today, 2008, 1, 117-125.

42 E. Payen, J. Grimblot and S. Kasztelan, J. Phys. Chem. B, 1987, 27, 6642-6648.

43 V. L. Parola, G. Deganello, C. R. Tewell and A. M. Venezia, Appl. Catal., A, 2002, 1, 171-180.

44 S. Badoga, K. C. Mouli, K. K. Soni, A. K. Dalai and J. Adjaye, Appl. Catal., B, 2012, 125, 67-84.

45 X. F. Zhou, S. T. Song, A. J. Duan, Z. Zhao, Y. J. Gong, X. L. Wang, J. M. Li, Y. C. Wei, G. Y. Jiang and J. Liu, ChemCatChem, 2015, 13, 1948-1960.

46 A. J. Duan, T. S. Li, Z. Zhao, B. J. Liu, X. F. Zhou, G. Y. Jiang, J. Liu, Y. C. Wei and H. F. Pan, Appl. Catal., B, 2015, 165, 763773.

47 H. D. Wu, A. J. Duan, Z. Zhao, T. S. Li, R. Prins and X. F. Zhou, J. Catal., 2014, 317, 303-317.

48 W. M. Hua, Y. H. Yue and Z. Gao, J. Mol. Catal. A: Chem., 2001, 1, 195-202. 